\title{
NEXT GENERATION STEEL FIBER REINFORCED SBR-LATEX MODIFIED NANO BASED CARBON CONCRETE
}

\author{
Showkath Ali Khan Zai ${ }^{1}$, P. S. Nagaraja ${ }^{2}$, Shashishankar. ${ }^{3}$, Sadath Ali Khan Zai ${ }^{4}$ \\ ${ }^{1}$ Research Scholar, Department of Civil Engineering, Jain University, Bangalore and Associate professor \&H.O.D \\ Dept. of civil Engineering, Islamiah Institute of Technology, Bangalore \\ ${ }^{2}$ Associate Professor, UVCE, Bangalore University, Bangalore, Karnataka, India \\ ${ }^{3}$ Professor and Head, Dept. of civil Engineering, AMC Engineering College, Bangalore \\ ${ }^{4}$ Associate Professor, UVCE, Bangalore University, Bangalore, Karnataka, India
}

\begin{abstract}
In reviewing technology advances through the centuries, it is evident that material development plays a key role. Considerable efforts are still being made in every part of the world to develop new construction materials. In the construction industry, concrete technology is heading towards entirely new era by way of using new generation Steel Fiber Reinforced SBR-Latex modified Nano based Carbon Concrete. High performance concrete (HPC) is a specialized series of concrete designed to provide several benefits in the construction of concrete structures. The present study aims to investigate the integration of Carbon Nanotubes (CNTs), SBR-Latex, Steel Fibers with HPC of a design mix of M60 grade of concrete. CNTs specifically designed for use with concrete composites as admixture Carbon Nanotubes is first dispersed in water and surfactant using an ultrasonic mixer, then combined with concrete as per state-of-the-art techniques. The various mechanical properties like Compressive, Flexural and Split tensile strength can be improved with the addition of low concentrations of CNT, steel fiber and SBR-latex in carbon concrete as compared to $H P C$.
\end{abstract}

Keywords: Carbon Concrete, High performance concrete, Fiber Reinforced Concrete, Carbon Nanotubes (CNTs), SBR-Latex, Steel Fibre, Compressive Strength, Flexural Strength and Split tensile strength. ****

\section{INTRODUCTION}

Concrete plays a vital role in civil engineering construction, High performance concrete is a concrete mixture, which possess high durability and high strength which satisfies certain criteria to overcome limitations of conventional concrete. HPC is not a commodity, but a range of products, each specially designed to satisfy the performance requirements for the intended application in the most effective way. HPC should necessarily satisfy both strength and durability requirements. This concrete contains one or more of cementations materials such as fly ash, Silica fume or ground granulated blast furnace slag and usually a super plasticizer. The term 'high performance' is somewhat pretentious because the essential feature of this concrete is that it's ingredients and proportions are specifically chosen so as to have particularly appropriate properties for the expected use of the structure such as high strength and low permeability. The use of mineral and chemical admixtures enhances the strength, durability and workability qualities to a very high extent. High Performance concrete works out to be economical, even though its initial cost is higher than that of conventional concrete because the use of High Performance concrete in construction enhances the service life of the structure and the structure suffers less damage which would reduce overall costs. The development of New Generation Carbon Nano Tubes SBR-Latex Modified Fiber Reinforced Concrete results from the materialization of a new science of concrete, a new science of admixtures and the use of advanced scientific equipment to monitor concrete microstructure. Therefore, many new macro-tomicro reinforcements have been utilized in order to increase the tensile strength and fracture toughness of concrete but all have led to marginal improvements but this can be achieved by integration of CNTs, SBR-Latex and Steel Fibers in carbon concrete.

\subsection{Literature Review}

High performance concretes (HPC) can be considered as a logical development of cement concretes in which the ingredients are proportioned and selected to contribute efficiently to the various properties of cement concrete in fresh as well as in hardened states.HPC concretes attributes which satisfy the performance criteria. Generally, concretes with higher strengths and attributes superior to Conventional concretes are desirable in the Construction Industry. HPC is defined in terms of strength and durability.HPC is used for concrete mixture which possess high workability, high strength, and high modulus of elasticity, high density, high dimensional stability, low permeability and resistant to chemical attack. Characteristics of concrete may improve in various ways. However Polymer modified reinforced concrete using SBR-Latex can show significant improvement in ductility and bonding properties, leading the material with higher toughness or ductility. This has led to an increasing interest in polymer modified fiber reinforced concrete and mortars in repair and retrofitting works. The 
potential of exploring the use of nanotechnology-based nano-filament, such as carbon nanotubes (CNTs), as reinforcement in recovering the mechanical properties of concrete. Very little attention has been dedicated to explore the use of nano-filaments in construction industry. Therefore, this study aspires to bridge the gap between nano-technology and construction engineering. Carbon nano-tubes (CNTs) have unique mechanical properties where their stiffness, strength, and resilience exceed any current material such that they offer tremendous opportunities for the development of fundamentally new material systems HPC is an engineered concrete possessing the most desirable properties during fresh as well as hardened concrete stages .[Gutierrez and Canovas (1996), Bharatkumar et al. (2001) and Kaushik et al. (2002)]. HPC is far superior to conventional cement concrete as the ingredients of HPC contribute most optimally and efficiently to the various properties [Long et al. (2002), Chang (2004), Balaguru and Najm (2004) and Wu et al. (2002)]. Various forms of reinforcement, typically in the form of rods or fibers, are added to concrete to compensate for its weakness in tension. CNT are expected to have several distinct advantages as a reinforcing material for cements as compared to more traditional fibers [Makar et al. (2005), AlRub and Tyson (2010) and Hlavacek et al. (2011)]. First, they have significantly greater strengths than other fibres, which should improve overall mechanical behaviour. [Barluenga G., F. Hernandez-Olivares ( 2004), Hanfeng Xu and Sidney Mindess ( 2004)], investigated the influence of water-to-cement ratio (W/C) and percentage of polymer in the setting time, rheology, physical and mechanical properties of a Styrene-Butadiene-Rubber (SBR) Latex Modified Mortar (LMM) and the dynamic properties, The material and mixture for LMM consists of Cement, sand. SBR latex, with solid content of 38\%.,[ Arun Kumar Chakraborty (2000)], studied the effects of SBR latex combined with three different fiber types: deformed steel fibers, of silica fume modified polymer cement mortar using two type of polymer emulsion methyl methacrylate butylacrylate ethylhexylacrylate (MBE), and styrene butadiene rubber (SBR) latex. Performance of this composite mortar was studied mainly in terms of compressive strength, flexural strength, toughness, water absorption and acid resistance. While limited research on Carbon Nanotubes (CNTs) has been focused around their incorporation within polymers very diminutive attention has been focused on assimilation of CNTs with cement and admixtures. Therefore, the research on integration of CNTs in cementatious materials is at a relatively novel stage; currently, very limited research regarding their effectiveness in enhancing the tensile strength or toughness of concrete has been conducted on carbon concrete. Hence an attempt has been made through the present experimental investigation to study the effect of CNTs, SBR-Latex, Steel Fibers with HPC of a design mix of M60 grade of concrete on the basic mechanical properties like compressive strength, split tensile strength and flexural strength of test specimens.

\section{EXPERIMENTAL PROGRAM}

The present experimental program consists of Casting and testing of test specimens for compressive strength, tensile strength and flexural strength which consists of five different concrete matrix $\operatorname{mix} 1, \operatorname{mix} 2, \operatorname{mix} 3, \operatorname{mix} 4$ and mix5. This experimental program is designed to investigate the integration of Carbon Nanotubes, SBR-Latex ,Steel fibre with High Performance Concrete of a design mix of M60 grade of concrete. The influence of the cementations material dosage, SBR-latex, carbon nano material, fibre content, and the mixing procedures on the mechanical properties of Steel Fiber Reinforced SBR-Latex modified Nano based Carbon Concrete together with the workability was studied by preparing different concrete matrix

\subsection{Materials}

In this present experimental investigation Ordinary Portland Cement of 53 Grade with a brand name Ultra Tech (Birla Super) is used. To ascertain the physical characteristics of the cement, tests were conducted in accordance with the Indian standards confirming to IS-12269:1987. Fractions of fine aggregates passing through $4.75 \mathrm{~mm}$ sieves and entirely retained on $150 \mu$ sieve are used. The test on fine aggregate was conducted in accordance with IS: $650-1966$ \& IS: 23861968 to determine specific gravity and fineness modulus. The Fine aggregate satisfied the requirement of grading Zone II as per IS: 383 - 1970 (Reaffirmed 2007). Crushed Granite stone with a maximum nominal size $12.5 \mathrm{~mm} \&$ down was adopted as the coarse aggregate. The tests on coarse aggregate were conducted in accordance with IS 2386-1963 to determine specific gravity and fineness modulus. In the present investigation for mix design of HPC, Glenium ACE 30, with Poly carboxylic based ethers as Super Plasticizer chemical admixture are used and SBRLatex supplied by BASF India Ltd. Bangalore. Micro silica a dry powder available in densified form and Ground Granulated Blast Furnace Slag (GGBFS) is a dry powder as supplied by M/s Ultra Tech Aditya Birla Group India Pvt. Ltd, Bangalore are used as mineral admixtures. Crimped end steel fibers having aspect ratio of 80,used and procured from Stewols India (Pvt) ltd, Nagpur-Maharashtra. Ordinary potable water was used for mixing and curing purpose. Multi walled carbon Nanotubes (MWCNT), which are water dispersible and mixed as per state-of-the-art techniques . Nanotubes was purchased from Global Nano Tech, Mumbai, India.

To determine the mix proportions for M60 grade concrete (HPC), tests on trial mixes were carried out and was finally selected with required workability of $25-50 \mathrm{~mm}$ slump, $8 \%$ of silica fume is replaced by weight of cement, $20 \%$ of GGBS, $0.1 \%$ of CNT by weight of cement, $0.7 \%$ of superplasticzier (Glenium ACE 30) $10 \%$ SBR latex by weight of cementatious material, $0.65 \%$ steel fbers by volume of concrete were used in the concrete mix in the present investigation. The final mix proportions for the matrix used in the investigation are shown in table 2.1 
Table 2.1: Properties of materials used

\begin{tabular}{|l|l|}
\hline Parameters & Specification \\
\hline Cement specific gravity & 3.12 \\
\hline Standard consistency & 32 \\
\hline Fineness Modulus of FA & 3.86 \\
\hline Specific gravity FA & 2.65 \\
\hline Specific gravity CA & 2.68 \\
\hline Fineness Modulus of CA & 6.10 \\
\hline Specific gravity Silica fume & 2.26 \\
\hline Specific gravity GGBS & 2.32 \\
\hline Aspect Ratio of Steel fiber & 80 \\
\hline CNT Density & $1.9 \mathrm{~g} / \mathrm{ml}$ \\
\hline Surface area of CNT & $540 \mathrm{M}^{2} / \mathrm{g}$ \\
\hline SBR Latex & $46.5 \%$ solids \\
\hline PH of Water & 6.8 \\
\hline
\end{tabular}

Table 2.2: Mix Proportion

\begin{tabular}{|l|l|l|l|l|l|l|}
\hline Ingredients & units & M60 & M60+CNT & M60+CNT+SBR & M60+CNT+Fiber & M60+CNT+Fiber+SBR \\
\hline Cement & $\mathrm{Kg} / \mathrm{m}^{3}$ & 450 & 450 & 450 & 450 & 450 \\
\hline $\begin{array}{l}\text { Fine } \\
\text { Aggregate }\end{array}$ & $\mathrm{Kg} / \mathrm{m}^{3}$ & 511 & 511 & 511 & 511 & 511 \\
\hline $\begin{array}{l}\text { Corse } \\
\text { aggregate }\end{array}$ & $\mathrm{Kg} / \mathrm{m}^{3}$ & 1135 & 1135 & 1135 & 1135 & 1135 \\
\hline Water & $\mathrm{Kg} / \mathrm{m}^{3}$ & 181.48 & 181.48 & 181.48 & 181.48 & 181.48 \\
\hline SBR & $\mathrm{Kg} / \mathrm{m}^{3}$ & - & - & 66.68 & - & 66.68 \\
\hline Silica Fume & $\mathrm{Kg} / \mathrm{m}^{3}$ & 29 & 29 & 29 & 29 & 29 \\
\hline GGBS & $\mathrm{Kg} / \mathrm{m}^{3}$ & 112.8 & 112.8 & 112.8 & 112.8 & 112.8 \\
\hline CNT's & $\mathrm{Liter}$ & 0.51 & 0.51 & 0.51 & 0.51 & 0.51 \\
\hline $\begin{array}{l}\text { Super } \\
\text { Plasticizer }\end{array}$ & $\mathrm{Kg} / \mathrm{m}^{3}$ & 4.0 & 4.0 & 4.0 & 4.0 & 4.0 \\
\hline W/C & & 0.36 & 0.36 & 0.36 & 0.36 & 0.36 \\
\hline Steel fiber & $\mathrm{Kg} / \mathrm{m}^{3}$ & - & - & - & 51.25 & 51.25 \\
\hline
\end{tabular}

\subsection{Test Specimens}

A series of specimens are chosen for the investigation and all are having a unique nominal standard dimensions for cubes $150 \mathrm{~mm}$, cylinders $150 \mathrm{~mm}$ dia. and 300mm height and prisms $100 \mathrm{X} 100 \mathrm{X} 500 \mathrm{~mm}$ respectively The test specimens consists of five different concrete matrix are as shown in table No.2.3

Table 2.3: Details of Test specimen

\begin{tabular}{|c|c|}
\hline Designation & Mix proportion details \\
\hline Mix 1 & $\begin{array}{l}\text { M60 } \quad: \quad(\text { Cement 71\% + Silica Fume 9\% + GGBS 20\%) } \\
\text { C:SF:GGBS:FA:CA:W } 1: 0.064: 0.191: 1.135: 2.52: 0.36\end{array}$ \\
\hline Mix 2 & $\begin{array}{l}\text { M60+CNT } \quad: \quad \text { (Cement 71\% + Silica Fume 9\% + GGBS 20\%+.10\% CNT) } \\
\text { C:SF:GGBS:FA:CA:W:CNT } \\
\text { 1:0.064:0.191:1.135:2.52:0.36:0.0011 }\end{array}$ \\
\hline Mix 3 & $\begin{array}{l}\text { M60+ CNT+SBR } \quad: \quad(\text { Cement } 71 \%+\text { Silica Fume } 9 \%+\text { GGBS 20\%+.10\%CNT+ 8\% SBR }) \\
\text { C:SF:GGBS:FA:CA:W:CNT:SBR } \\
\text { 1:0.064:0.191:1.135:2.52:0.36:0.0011:0.008 }\end{array}$ \\
\hline Mix 4 & $\begin{array}{l}\text { M60+CNT+ FIBER } \quad: \quad(\text { Cement } 71 \%+\text { Silica Fume } 9 \%+\text { GGBS 20\%+.10\%CNT+ .65\% FIBER) } \\
\text { C:SF:GGBS:FA:CA:W:CNT:FIBER } \\
\text { 1:0.064:0.191:1.135:2.52:0.36:0.0011:51.025 }\end{array}$ \\
\hline Mix 5 & $\begin{array}{l}\text { M60+CNT+ FIBER+SBR : } \quad \text { (Cement71\% +Silica Fume } 9 \%+\text { GGBS } 20 \%+.10 \% \text { CNT+ .65\% } \\
\text { FIBER+8\% SBR) } \\
\text { C:SF:GGBS:FA:CA:W:CNT:SBR:FIBER } \\
1: 0.064: 0.191: 1.135: 2.52: 0.36: 0.0011: 0.008: 51.025\end{array}$ \\
\hline
\end{tabular}




\subsection{Casting the Specimens}

In casting the specimen, Weigh Batching is used for the experimental study. Cement is weighed \& slowly mixed with weighed Silica fume and GGBS the whole dry sample is mixed for 5 minutes. The Known weighed Fine aggregate, coarse aggregate, SBR Latex and steel fibers were weighed $\&$ mixed with above ternary blended mixer then water is measured in a measuring jar and mixed with Super plasticizer and dispersed CNTs of known volume. The Concrete mix is mixed until a uniform homogeneous mix is obtained, the mixing time should not exceed 3-4 minutes. Care should be taken when using CNTs. The dispersed solution of CNTs is added to the mix \& the mixing is continued until the lump free homogeneous mix is obtained. For preparing specimens in the laboratory, care was taken to maintain the quality of concrete by standardizing the materials, proper batching of material, and proper mixing of materials, proper method of compaction, adequate compaction, compaction time, initial hardening, curing and method of testing.

\section{METHODOLOGY OF TEST}

In the present study Compressive strength, Split tensile strength \& flexural strength are taken in to account. The experimental setup, casting, curing of specimen and testing procedure in accordance with as per IS 516-1959 for determination of compressive strength, split tensile strength and flexural strength respectively.

\subsection{Results and Discussions}

The experimental values obtained for different concrete mixes used in the present investigation are tabulated in following tables and corresponding graphs.

\subsubsection{Results for Compressive Strength}

The compressive strength is the main criteria for the purpose of structural design, the compression tests are relatively easy to carry out. The test for determining compressive strength for concrete, employs a cube specimen of $150 \mathrm{~mm}$ size and cured for 3, 7, and 28 days which is subjected to uniaxial compression in a compression testing.

Table 3.1: Compressive Strength for all mixes

\begin{tabular}{|c|c|c|c|c|c|}
\hline \multicolumn{6}{|c|}{ Compressive Strength (N/mm2) obtained } \\
\hline AGE & Mix 1 & Mix 2 & Mix 3 & Mix 4 & Mix 5 \\
\hline 3days & 32 & 44.18 & 37.92 & 48.62 & 39.47 \\
\hline 7days & 48 & 61.16 & 59.86 & 66.48 & 60.28 \\
\hline 28days & 64.01 & 76.65 & 72.58 & 80.55 & 74.23 \\
\hline
\end{tabular}

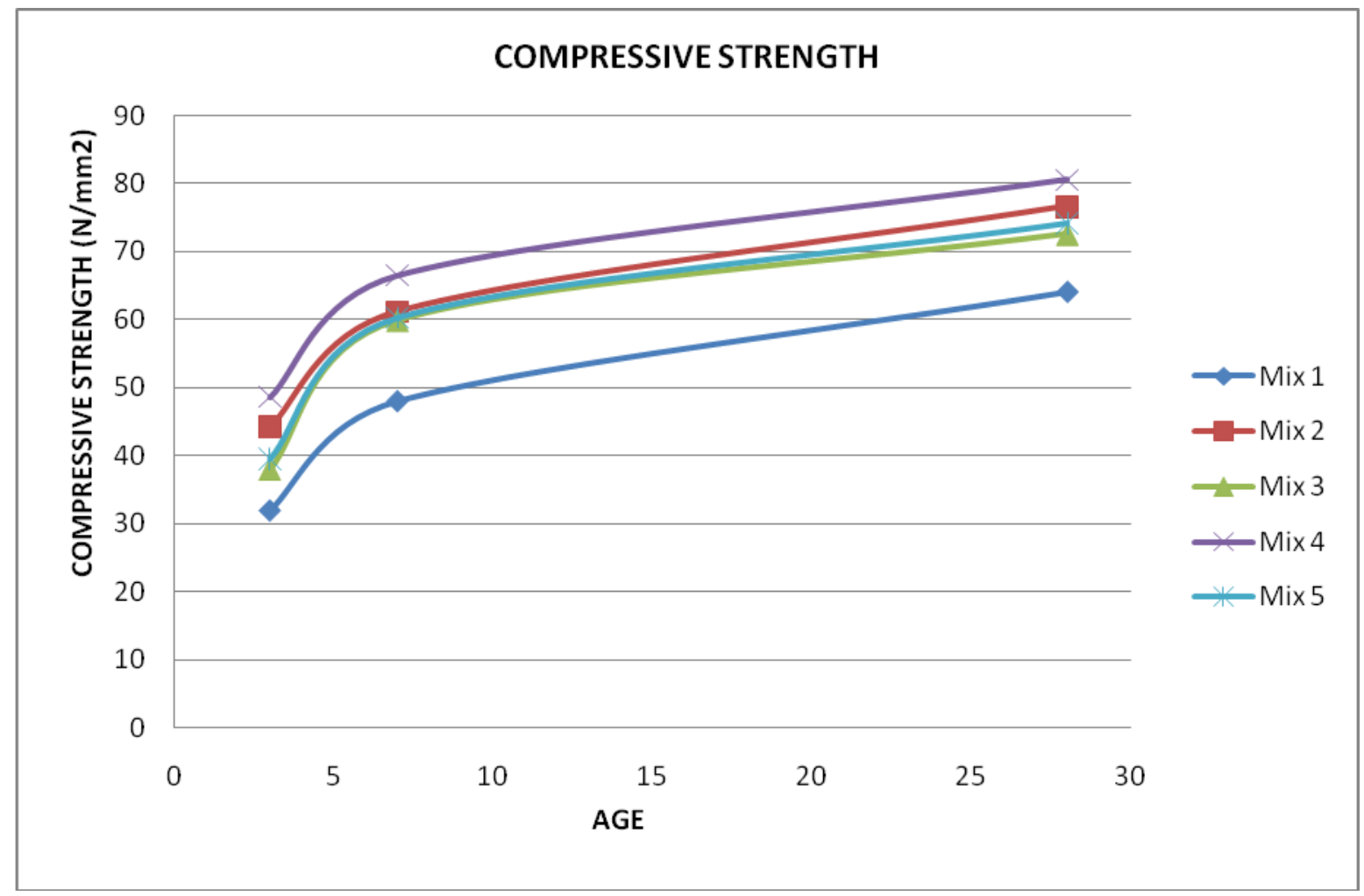

Graph 1: Combined compressive strength for all mix 


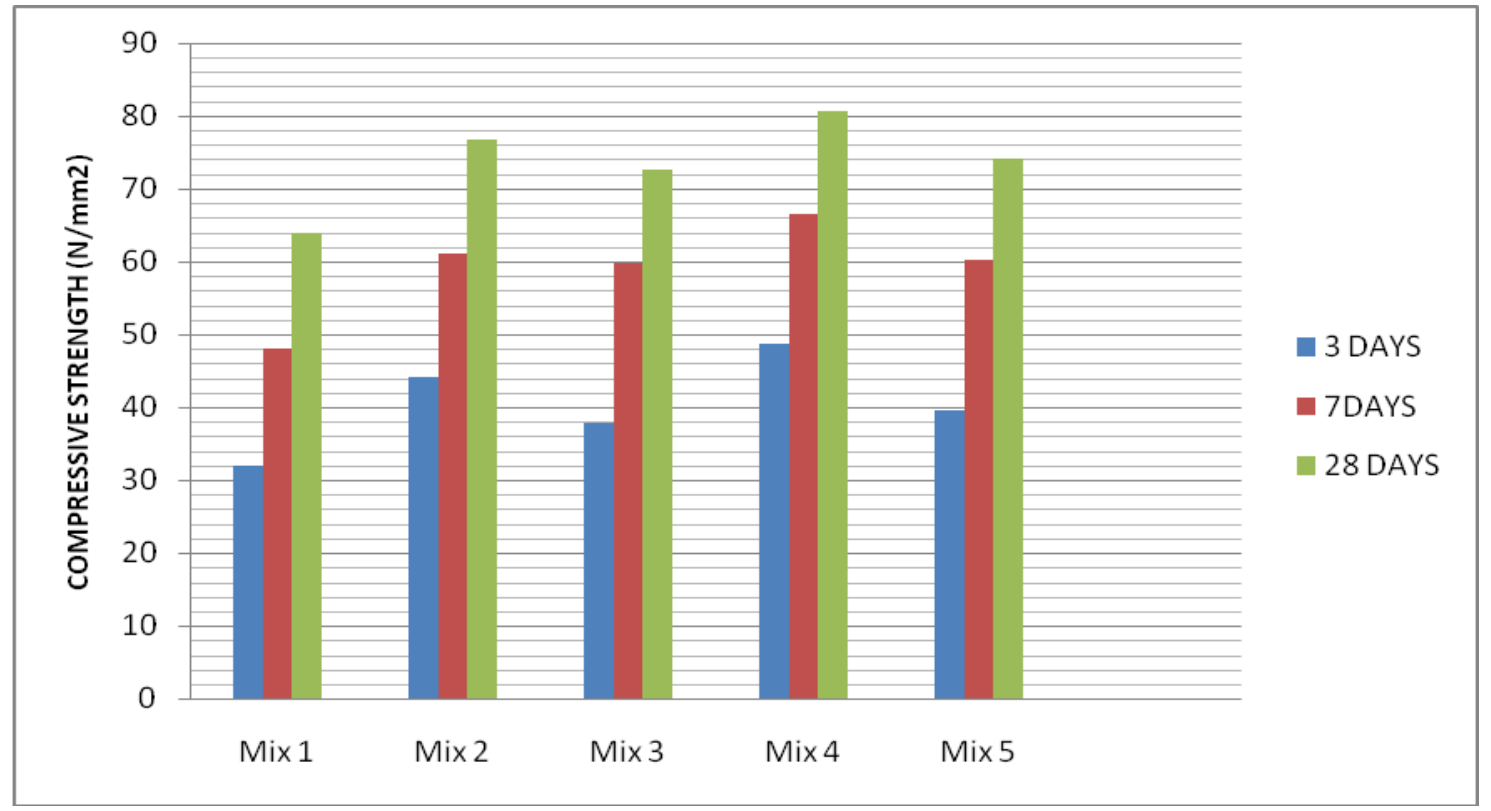

Graph 2: Combined compressive strength for all mix

\subsubsection{Results for Split Tensile Strength}

This is an indirect test for tensile strength of concrete. This method is developed in Brazil and has come in to general use and been standardized throughout the world. The specimen is a $150 \Phi \times 300 \mathrm{~mm}$ cylinder made and cured in the same manner as similar to compressive test. Two wooden strips are placed. One at the top and the other at the bottom of the specimen and the same is loaded in compression. The tensile strength computed in this manner is apparently about $15 \%$ higher than that determined by direct tension tests. In order to obtain the split tensile strength for 3,7 and 28 days, tests are conducted on cylinders. The results of split tensile strength test were tabulated below.

Table 3.2: Split Tensile Strength For All Mixes

\begin{tabular}{|l|l|l|l|l|l|}
\hline \multicolumn{7}{|l|}{ Split Tensile Strength (N/Mm2) obtained } \\
\hline AGE & Mix 1 & Mix 2 & Mix 3 & Mix 4 & Mix 5 \\
\hline 3days & 1.86 & 2.19 & 1.98 & 2.4 & 2.14 \\
\hline 7days & 2.17 & 3.15 & 2.57 & 3.94 & 2.98 \\
\hline 28days & 2.8 & 4.08 & 3.12 & 6.12 & 3.85 \\
\hline
\end{tabular}

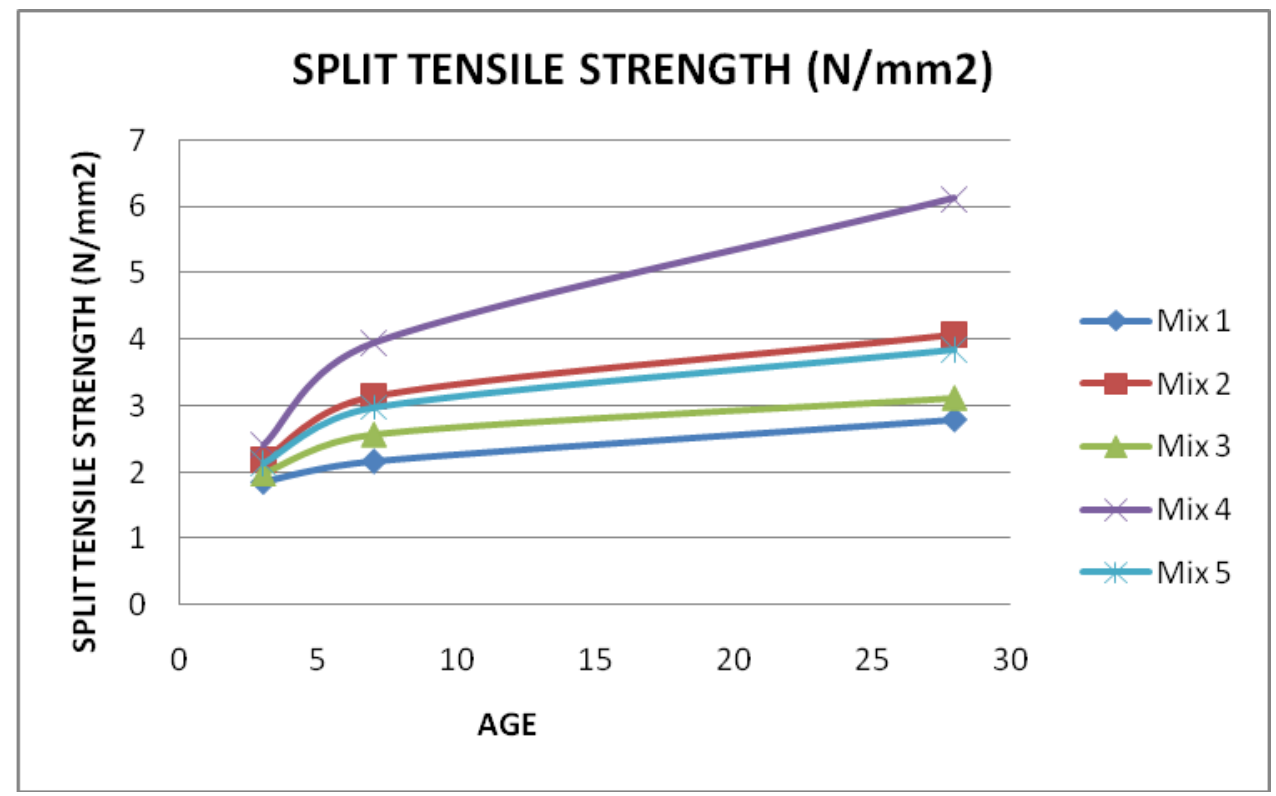

Graph.3: Combined Split Tensile strength for all mix 


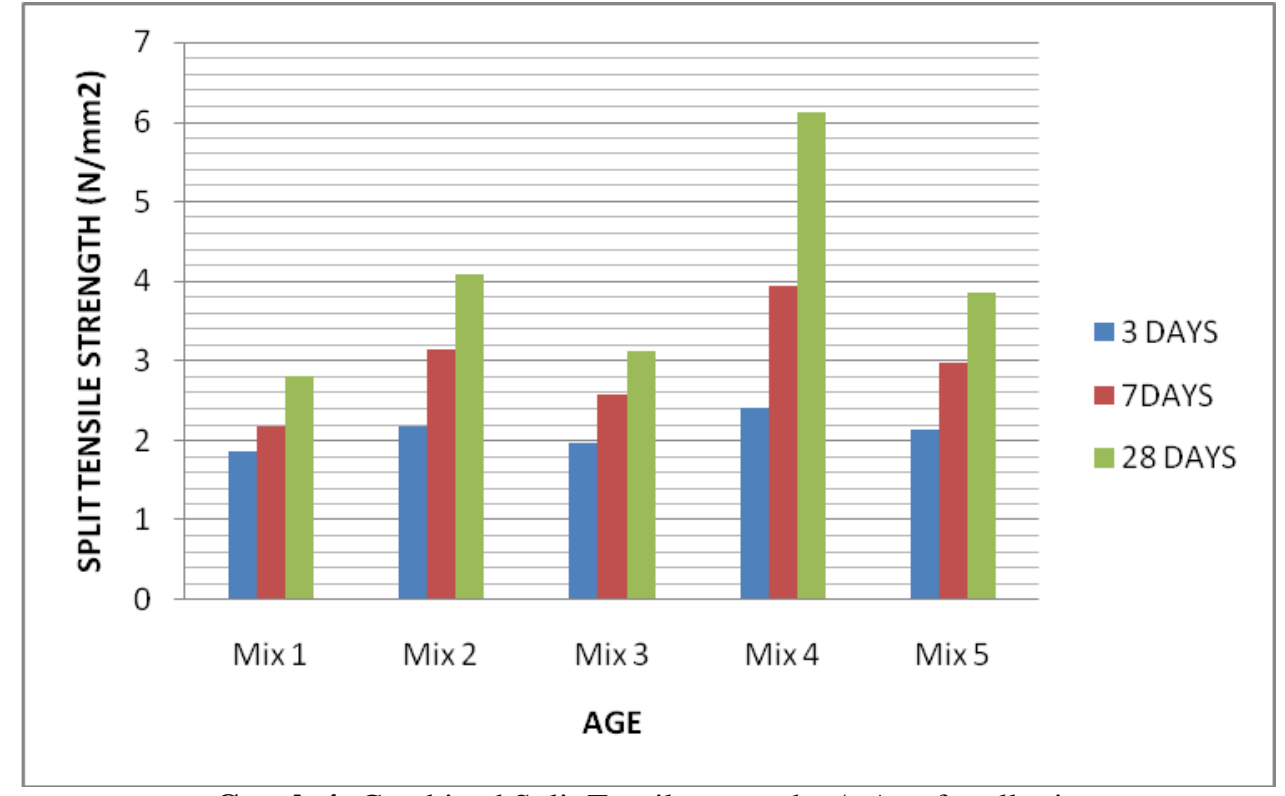

Graph.4: Combined Split Tensile strength v/s Age for all mix

\subsubsection{Results for Flexural Strength}

When concrete is subjected to bending, Tensile, compressive stresses and in many cases direct shearing stresses occur. The most common example of concrete structure subjected to flexure are highway pavements and the strength of concrete for pavements is commonly evaluated by means of bending tests on $100 \times 100 \times 500 \mathrm{~mm}$ beam specimens. Flexural strength is expressed in terms of "Modulus of rupture" which is the maximum tensile (or compressive) stress at rupture.

Table 3.3: Flexural Strength For All Mixes

\begin{tabular}{|l|l|l|l|l|l|}
\hline \multicolumn{6}{|l|}{ FLEXURAL STRENGTH (N/mm2) obtained } \\
\hline AGE & Mix 1 & Mix 2 & Mix 3 & Mix 4 & Mix 5 \\
\hline 3days & 2.12 & 3.97 & 2.52 & 3.27 & 4.21 \\
\hline 7days & 2.97 & 5.02 & 3.62 & 4.19 & 6.32 \\
\hline 28days & 4.43 & 7.48 & 5.95 & 6.23 & 8.33 \\
\hline
\end{tabular}

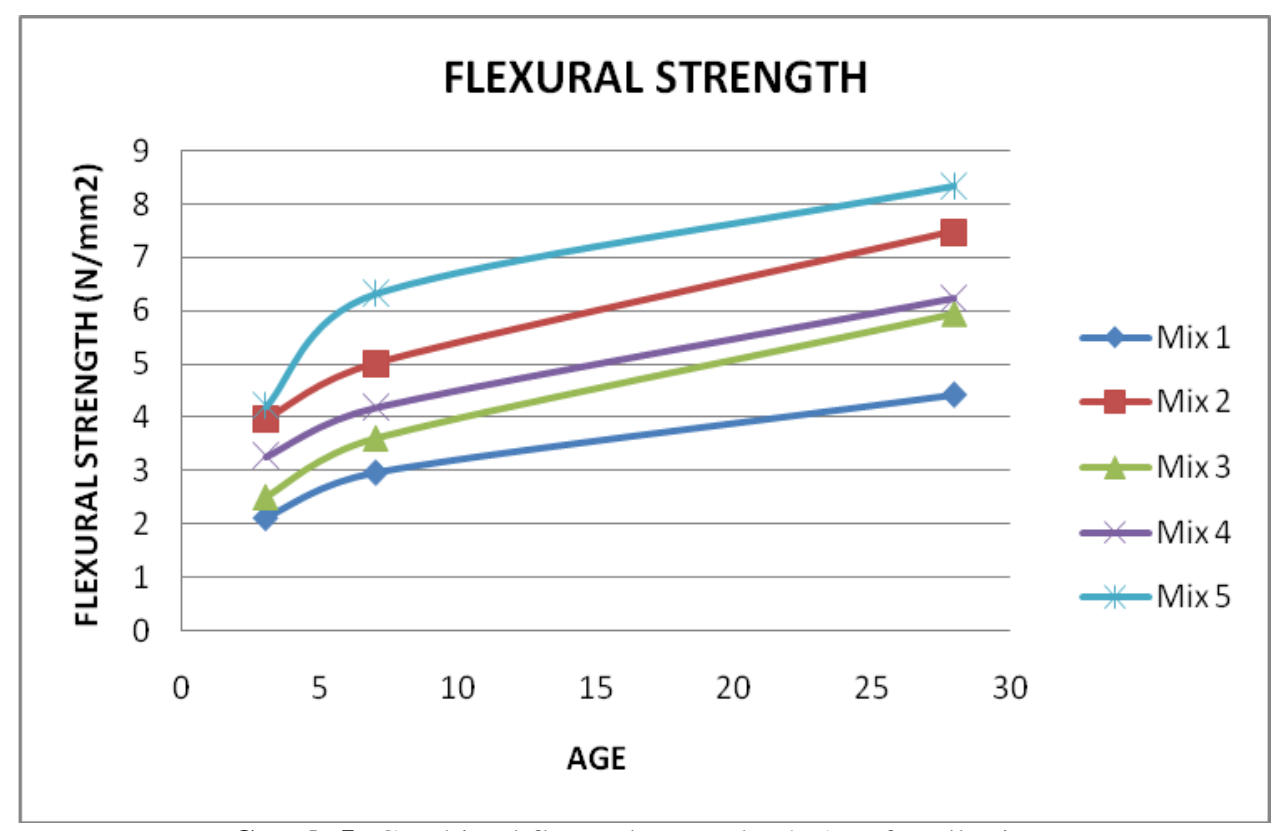

Graph.5: Combined flexural strength v/s Age for all mixes 


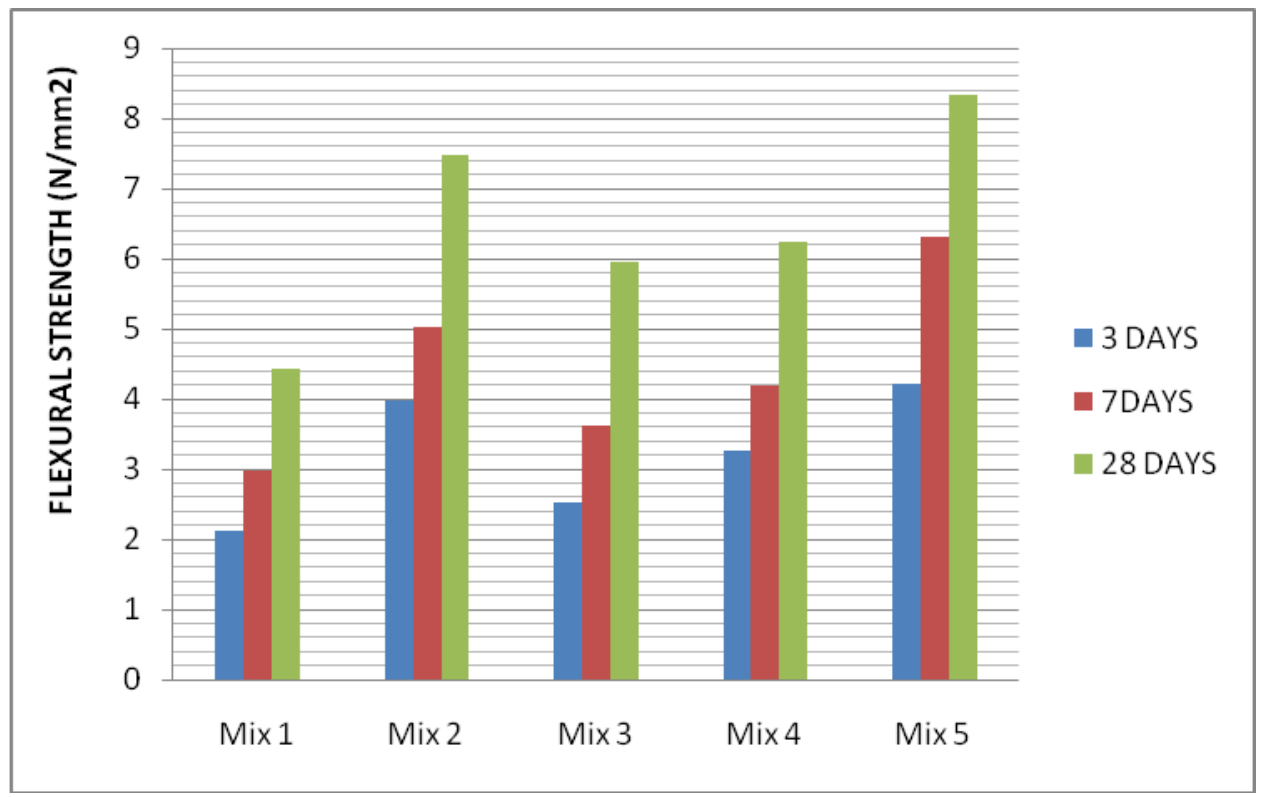

Graph.6: Combined flexural strength v/s Age for all mixes

\section{SUMMARY AND CONCLUSION}

The Experimental program deals with behavior of Steel Fiber Reinforced SBR-Latex modified Nano based Carbon Concrete, in which High Performance Concrete is modified with CNT, SBR Latex, and Steel fiber. A concrete mix of grade M60 was designed to which CNT's, SBR latex and Steel Fiber were added. The test specimens consists of Cubes ,cylinders and prisms for five different concrete matrix such as Mix1, Mix2 Mix3, Mix4, and Mix5, and are tested for compression strength, split tensile strength and flexural strength respectively.

Based on the results of the experimental investigation the following conclusion are drawn.

- A number of variables can cause changes in the physical and mechanical behaviour of concrete. These include the composition of concrete mix, type of aggregate and their shape, admixtures and addition of fibres and other complementary reinforcement.

- The rate of gain of 28 days compressive strength is highest for Mix 4 (M60+CNT+FIBER) matrix specimen in comparison with other concrete matrices used in this investigation The increase in compressive strength for Mix 4 is $25.83 \%, \quad 5.08 \%, 10.98 \%$ and $8.51 \%$ respectively, compaired with respect to Mix1 (M60 control), Mix2 (M60+CNT), Mix3(M60+CNT+SBR) and Mix5(M60+CNT+Fiber+SBR) respectively .

- The rate of gain of the 28 days split tensile strength is highest for Mix 4 (M60+CNT+FIBER) sspecimen in comparison with other concrete matrices used in this investigation. The split tensile strength of Mix 4 is $118.57 \%, 50.12 \%, 96.15 \%$ and $58.96 \%$ respectively, compaired with respect to Mix1 (M60 control), Mix2 (M60+CNT), Mix3(M60+CNT+SBR) and Mix5(M60+CNT+Fiber+SBR).

- The rate of gain of the 28 days flexural strength is highest for Mix 5(M60+CNT+Fiber+SBR) specimen in comparison with other concrete matrices used in this investigation. The flexural strength of Mix 5 is $88.03 \%$, $18.04 \%, 40.2 \%$ and $33.70 \%$ respectively, compaired with respect to Mix1 (M60 control), Mix2 (M60+CNT), Mix3(M60+CNT+SBR) and Mix4(M60+CNT+Fiber).

From this experimental investigation, it is observed that High performance concrete modified with CNT, SBR and Fiber (MIX 4 and MIX 5) behave much better with regards to compressive strength and split tensile strength where as MIX 5 shows significant increase in flexural strength as compared to other mixes used.

\section{REFERENCES}

[1] Gutierrez, P. A. Canovas, M. F. (1996): HighPerformance Concrete: Requirements for Constituent Materials and Mix Proportioning, ACI Materials Journal, 93 (3), pp. 233-244.

[2] Arun Kumar Chakraborty, Sekhar Chandra Dutta, Prodosh Sen, and Indrajit Ray(L), "Improved Performance of Silica Fume Modified Mortar due to Addition of Polymer Emulsions," Journal of Polymer Materials, Vol.17, No.1, March., 2000, pp.53-62

[3] Bharatkumar, B. H. Narayanan R. Raghuprasad, B. K. Ramachandramurthy, D.S. (2001): Mix proportioning of high performance concrete, Cement and Concrete Composites, 23, pp.71-80.

[4] Kaushik, S. K. Kumar, V. Bhargava, V. P (2002): Mechanical properties of High-strength concrete: A review, ICJ, pp.505-520

[5] Long, G. Wang. X. Xie, Y. (2002): Very-highPerformance Concrete with ultrafine powders, Cement and Concrete Research, Pergamon, 32, p.p 601-605.

[6] Wu, K. R. Yan, A, Yao, W. Zhang, D. (2002): The influence of RPCA on strength and fracture toughness of HPC, Cement and Concrete Research, 32, pp. 351355. 
[7] Balaguru, P. Najm, H. (2004): High Performance Fiber Reinforced Concrete Mixture proportions with High Fiber volume Fractions, ACT Material Journal, 101 (4), pp. 281-285.

[8] Barluenga G., and Hernandez-Olivares F(L)., "SBR Latex Modified Mortar Rheology and Mechanical Behaviors," Cement and Concrete Research,Vol.34, 2004, pp. 527-535.

[9] Chang, P. (2004): An approach to optimizing mix design for properties of high Performance concrete, Cement and Concrete Research, 34, pp. 623-629.

[10] Hanfeng $\mathrm{Xu}$, and Sidney Mindess, "The Flexural Toughness of High Strength Fiber Reinforced Concrete with Styrene-Butadiene Latex," Progress in Structural Engineering, Mechanics and Computation, Zingoni (ed.), 2004, pp.1545-1549.

[11] Makar, J. Margeson, J. Luh, J. (2005): Carbon nanotube/cement composites early results and potential applications, 3rd International conference on construction materials: Performance, Innovations and Structural implications, Vancouver, B.C., pp. 1-10.

[12] Al-Rub, R. K. A. Tyson, B. M. (2010): Assessment the potential of using Carbon nanotubes reinforcements for improving the tensile/flextural strengthand fracture toughness of Portland cement paste for damage resistant concrete transportation infrastructures, Texas transportation Institute Zachry Department of civil Engineering texas A\&M University

[13] Hlavacek, P. Smilauer, V. Padevet, P. Nasibulina, L. Nasibulin, A. G. (2011): Cement grains with surfacesynthesized carbon nanofibers mechanical properties and nanostructure, Brno, Czech Republic, EU, pp. 21 23 